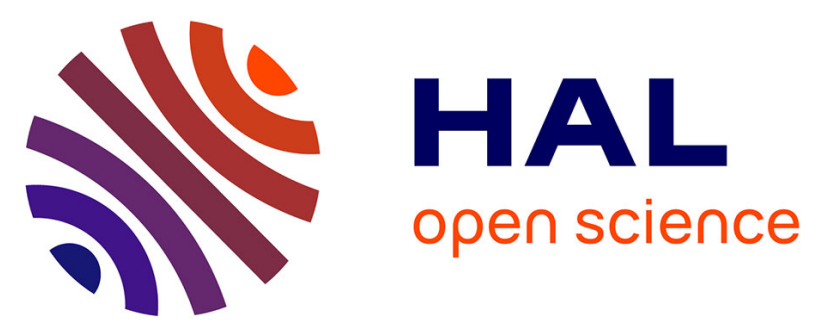

\title{
Femtosecond Bessel filaments for high aspect-ratio and taper-free micromachining of dielectrics
}

F. Courvoisier, M.K. Bhuyan, M. Jacquot, P.-A. Lacourt, L. Furfaro, M. J. Withford, J.M. Dudley

\section{- To cite this version:}

F. Courvoisier, M.K. Bhuyan, M. Jacquot, P.-A. Lacourt, L. Furfaro, et al.. Femtosecond Bessel filaments for high aspect-ratio and taper-free micromachining of dielectrics. Conference on Lasers and Electro-Optics (CLEO) 2010, May 2010, San Jose, United States. 10.1364/CLEO.2010.CMBB3 . hal-00589625

\section{HAL Id: hal-00589625 \\ https://hal.science/hal-00589625}

Submitted on 23 Apr 2021

HAL is a multi-disciplinary open access archive for the deposit and dissemination of scientific research documents, whether they are published or not. The documents may come from teaching and research institutions in France or abroad, or from public or private research centers.
L'archive ouverte pluridisciplinaire HAL, est destinée au dépôt et à la diffusion de documents scientifiques de niveau recherche, publiés ou non, émanant des établissements d'enseignement et de recherche français ou étrangers, des laboratoires publics ou privés. 


\title{
Femtosecond Bessel filaments for high aspect-ratio and taper-free micromachining of dielectrics
}

\author{
F. Courvoisier ${ }^{1 *}$, M. K. Bhuyan ${ }^{1}$, M. Jacquot ${ }^{1}$, P.A. Lacourt ${ }^{1}$, L. Furfaro ${ }^{1}$, M.J. Withford ${ }^{2}$ and J.M. Dudley ${ }^{1}$ \\ ${ }^{1}$ FEMTO-ST Institute, Department of Optics P.M. Duffieux, UMR CNRS 6174, Université de Franche-Comté, 25030 Besançon, France \\ ${ }^{2}$ CUDOS and MQ Photonics, Department of Physics, Macquarie University, New South Wales, 2109, Australia \\ *francois.courvoisier@femto-st.fr
}

\begin{abstract}
Femtosecond Bessel beams are demonstrated for high aspect ratio machining in the filamentation regime with water assistance. Taper-free microchannels and micro-trenches are demonstrated with aspect ratio up to 40 and diameters down to $2 \mu \mathrm{m}$.
\end{abstract}

Femtosecond (fs) laser micromachining is a versatile materials processing technology suitable for fabricating a wide range of structures in transparent media. It holds particular promise for microfluidics applications where high quality sub-10 $\mu \mathrm{m}$ channels are essential structures in the development of system-scale lab-on-chip and DNA analysis. Femtosecond microchannel machining in various glasses has been the subject of many previous studies and, whilst debris redeposition and tapering effects precludes high aspect ratio microchannel fabrication using simple frontsurface illumination in air, several more sophisticated approaches have been developed. These include micromachining in vacuum, micromachining with filamentary propagation, micromachining combined with selective etching, and micromachining the reverse side of the sample using water immersion for debris removal [1].

These previous studies, however, have all used femtosecond lasers with transverse Gaussian beam intensity profiles. In this paper, we describe an alternative and original approach using high-aspect ratio Bessel beams to overcome many of the difficulties associated with femtosecond micromachining with Gaussian beams. Although fs Bessel beam machining has been investigated for laser processing in metals, laser surface nanoprocessing [2] and index modification in glass [3], to our knowledge, the results here are the first to describe its application to the fabrication of glass microchannels and high aspect ratio micromachining. Our results show that Bessel beams can be used to generate taper-free channels of around $\sim 2 \mu \mathrm{m}$ diameter and $\sim 80 \mu \mathrm{m}$ length in glass in a straightforward setup without the need for any sample translation. We interpret these results in terms of a specific regime of stable filament formation [4], and identify a working window for the practical use of Bessel beams for glass micromachining.

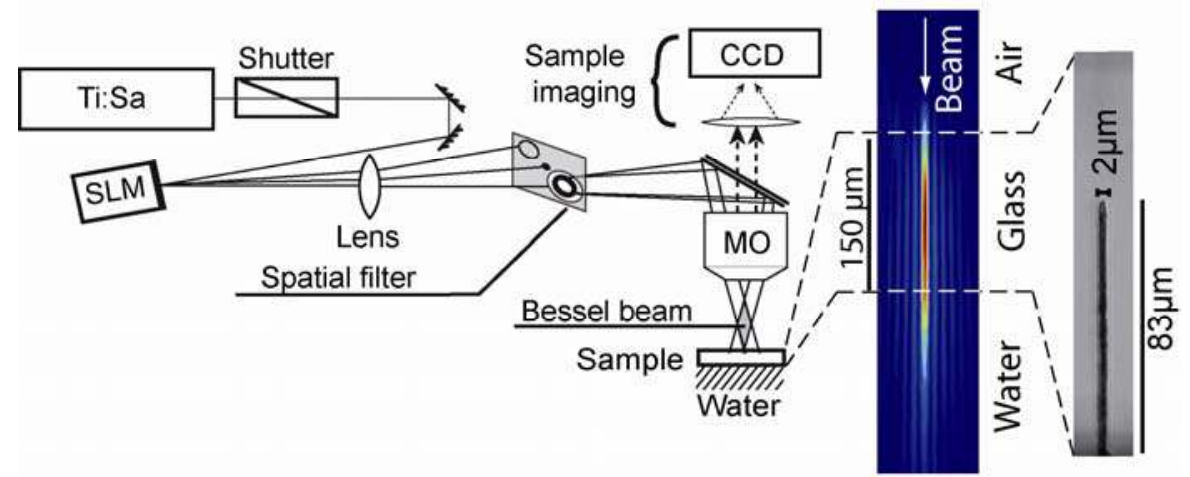

Fig. 1 : Setup (left) and focusing geometry (middle) of the Bessel beam at the sample exit side. The central core is $1.5 \mu \mathrm{m}$ FWHM

(Right) example of taper-free microchannel drilled in glass without translation (1000 laser shots, $50 \mathrm{~Hz}, 7.6 \mu \mathrm{J} / \mathrm{pulse}$ )

Our experimental setup is shown in Fig. 1. We generate a Bessel beam using a spatial light modulator (SLM) to imprint the spatial phase of an axicon onto the beam of an amplified $100 \mathrm{fs}$ Ti:Sapphire laser operating at $800 \mathrm{~nm}$. The Bessel beam is focused in a Corning 0211 glass sample that rear side is in contact with distilled water. Fig. 2 presents a series of results showing how the characteristics of microchannels machined using Bessel beams vary with input pulse parameters. Fig 2(a) shows measured DIC (Differential Interference Contrast) images of machined channel structures for incident pulse energies of $7 \mu \mathrm{J}$ at a repetition rate of $100 \mathrm{~Hz}$. We can clearly identify regions of drilled channels (black regions) as well as refractive-index modification (light regions). In contrast to comparable studies carried out using Gaussian beams the channels and structures in Fig. 2(a) are free of visible tapering over their length, and we stress again that these results are obtained without any sample translation. In the regime where machining is carried out with less that 500 shots, the formation of channels appears stochastic from run-to-run. 
Nonetheless, for more than 500 shots, the channel properties (length and diameter) stabilize significantly which is consistent with an incubation process.

The results of our detailed study of channel morphology as a function of incident pulse energy are shown in Fig. 2(b). In these experiments, we observed a clear threshold effect such that channel structures were only observed for energies greater than $6.2 \mu \mathrm{J}$. Below this energy we observed refractive index modifications. Close to threshold ("onset" regime), the individual channels within the series of 10 machined at each pulse energy displayed large variation in length and diameter. However we observed a clear increase in channel length and a similar increase in channel diameter with energy and, significantly, greatly improved stability within the energy range $6.8-8 \mu \mathrm{J}$. Above $8 \mu \mathrm{J}$, a significant qualitative change is observed. Specifically, the individual channels within the series of 10 that were machined at each pulse energy displayed large variation in their length and diameter. We also see from the DIC images that the machined structure exhibits significant longitudinal variability with both drilled channel (dark) and index-modified tracks (light) clearly apparent. Moreover, within the drilled channels, there is significant transverse variation. As indicated in the figure, this defines a boundary between "stable" and "unstable" channel formation. In the stable regime, channel termination corresponds to a decrease of the intensity at the extremity of the Bessel beam below a minimum threshold for efficient ablation.

Recent studies of fs Bessel beam propagation in Kerr media allow us to suggest a scenario for channel formation in terms of filamentation. Specifically, our results are consistent with the fact that Bessel beam filamentation establishes a single and continuous plasma channel of constant density whose diameter is determined only by the central lobe [4], as it is the case in our experiment. A filamentation mechanism is also consistent with a fluence threshold marking a transition between stable and unstable plasma channel formation, as noted in [4]. This transition arises because the formation and propagation of stable Bessel filaments requires that the intensity at the front surface is sufficiently low to avoid the immediate triggering of nonlinear effects when the beam enters the sample.

(a) Evolution with number of shots

(b) Evolution with Energy per pulse
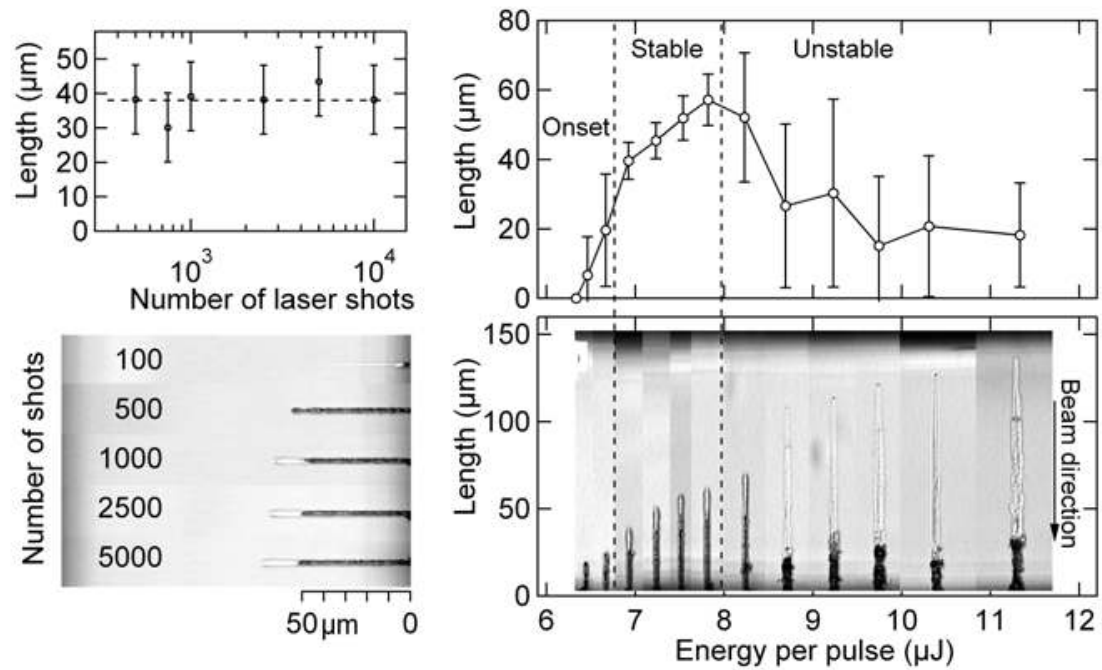

Fig. 2 (a) Evolution of channel length (top) and morphology (bottom) with number of laser shots at $7 \mu \mathrm{J} / \mathrm{pulse}, 100 \mathrm{~Hz}$.

(b) Evolution of channel length (top) and morphology (bottom) with energy per pulse (100Hz, 1000 shots)

As a conclusion, our results clearly show the potential of femtosecond Bessel beams for high aspect ratio microchannel machining in glass without sample translation. Our studies have determined a practical working window where amplified fs lasers can be used to generate taper-free channels of $2 \mu \mathrm{m}$ diameter and with aspect ratios up to 40 [5]. A novel interpretation of our results in terms of a nonlinear filamentation mechanism has been proposed. The variations of the properties of the machined channels with beam parameters and consequences for high aspect ratio micromachining will be discussed. We anticipate that these results will motivate further studies of the practical application of Bessel beams in materials processing and fundamental studies of the Bessel beam lightmatter interaction.

[1] Y. Li et al, "Three-dimensional hole drilling of silica glass from the rear surface with femtosecond laser pulses,” Opt. Lett. 26, 1912 (2001)

[2] F. Courvoisier et al "Surface nanoprocessing with nondiffracting femtosecond Bessel beams," Opt. Lett. 34, 3163-3165 (2009).

[3] J. Amako et al, "Microstructuring transparent materials by use of nondiffracting ultrashort pulse beams generated by diffractive optics," J. Opt. Soc. Am. B 20, 2562-2568 (2003).

[4] P. Polesana et al, "Filamentation in Kerr media from pulsed Bessel beams," Phys. Rev. A 77, 043814 (2008)

[5] M. K. Bhuyan et al, "High aspect ratio taper-free microchannel fabrication using femtosecond Bessel beams", submitted. 